$17^{\text {th }}$ International Congress of Metrology, 07001 (2015)

DOI: $10.1051 /$ metrology $/ 201507001$

(C) Owned by the authors, published by EDP Sciences, 2015

\title{
Traceability for Mercury Measurements
}

\author{
Paola Fisicaro ${ }^{1}$, Hugo Ent ${ }^{2}$, Claudia Swart ${ }^{3}$, Heidi Goenaga-Infante ${ }^{4}$, Milena Horvat ${ }^{5}$ \\ ${ }^{1}$ Laboratoire national de métrologie et d'essais (LNE), 1 rue Gaston Boissier, 75724 Paris Cedex 15, France, Paola.Fisicaro@lne.fr.
}

2 VSL Thijsseweg 11, 2629 JA Delft, Netherlands

${ }^{3}$ Physikalisch technische Bundesanstalt (PTB), Braunschweig, 38116, Germany.

4 LGC, Queens Road,Teddington TW11 OLY, UK

5 J. Stefan Institute (IJS), Jamova cesta 39, 1000 Ljubljana, Slovenia

\begin{abstract}
Résumé. Le mercure est connu pour la gravité de ses effets neurotoxiques et il suscite beaucoup d'inquiétude du fait de ses conséquences néfastes sur les enfants à naitre et les nourrissons. La capacité du mercure à se propager dans l'environnement rende nécessaire d'agir à niveau global pour s'attaquer au problème de la pollution dont il est à l'origine. Malgré la réglementation qui se met en place au niveau international et européen afin de limiter et contrôler les émissions et les relargages de mercure de nature anthropique, une infrastructure métrologique capable de fournir des résultats fiable et comparable pour les mesures du mercure et de ses espèces dans les différents compartiments environnementaux n'a pas encore été mise en place. Cet article présente les actions principales qui seront menées dans la cadre d'un projet de recherche conjointe dans le cadre du programme européen de recherche en métrologie (EMRP).
\end{abstract}

\section{Context}

Mercury in its many chemical forms is highly toxic to human, animal and environmental health. Its ability to accumulate in terrestrial and aquatic biosystems makes it an insidious threat to environmental sustainability. Its long lifetimes and ability to be transported in air over long distances mean that it is ubiquitous to all environmental compartments and is a pollutant of global concern. The increase in the presence of mercury in the environment has been due to human activity over the last hundred years, and whilst legislation is in place to limit human releases, the assessment of the ongoing effect of mercury on humans and the environment is critically dependent on accurate measurements to assess concentrations and trends. This challenge is complicated by the various chemical forms of mercury and its presence in a number of different matrices.

Despite this, the measurement infrastructure to provide traceable measurements of forms of mercury that are currently regulated and to underpin advanced analytical techniques to support the next generation of environmental mercury measurement is absent in Europe, and globally.

At European level, directives concerned with the measurement of emissions and concentrations in air (Directive 2004/107/EC [1], Directive 2010/75/EU [2]) are awaiting the arrival of a solid metrological infrastructure providing traceability and reduced uncertainties for mercury measurements to enable the introduction and subsequent enforcement of target values for mercury, and to ensure the reliability and comparability of measurement results, as is the case for similar toxic elements covered by legislation.

At international level, in order to prevent global environmental pollution and damage to health caused by mercury, a new convention named the "Minamata Convention on Mercury" has been agreed [3].

The Convention is a global treaty to protect human health and the environment from the adverse effects of mercury. It was agreed at the fifth session of the Intergovernmental Negotiating Committee in January 2013 and adopted at the UNEP Diplomatic Conference held in October 2013 in Japan.

The major highlights of the Minamata Convention on Mercury include a ban on new mercury mines, the phaseout of existing ones, control measures on air emissions, and the international regulation of the informal sector for artisanal and small-scale gold mining.

The Convention draws attention to a global and ubiquitous metal that, while naturally occurring, has broad uses in everyday objects and is released to the atmosphere, soil and water from a variety of sources. Controlling the anthropogenic releases of mercury throughout its lifecycle has been a key factor in shaping the obligations under the convention.

Due to its highly toxic nature, the use of mercury is being phased out for many applications and limited to a mass fraction of mercury in products of less than $1000 \mathrm{mg} / \mathrm{kg}$ in current usage or new application. Mercury is classified as a priority hazardous substance (PHS) due to its

paola.fisicaro@lne.fr

This is an Open Access article distributed under the terms of the Creative Commons Attribution License 4.0, which permits unrestricted use, distribution, and reproduction in any medium, provided the original work is properly cited. 
persistent, bio-accumulative and toxic properties. For PHS, European Member States are legally obliged to progressively reduce discharges, emissions and losses to zero within the next 20 years. Unfortunately mercury is still entering the European environment in large amounts and with large uncertainties. It is also entering via transboundary transport from other parts of the world. Because of the global transport of mercury, releases in other parts of the world are as important to Europeans as domestic emissions. In the UNEP 2013 document "Global Mercury Assessment" the global emissions to air from anthropogenic sources were estimated at 1960 tonnes in 2010 [4]. Despite recent progress in improving the available knowledge base, these emissions estimates still have large uncertainties, giving a range of between 1010 and 4070 tonnes. Other potentially important sectors identified as emitters, whose effect has not yet been quantified, include the use of mercury in vinylchloride monomer production, secondary metals production and ferro-alloys, oil and gas extraction, and transport.

Overall, indications are that mercury emissions from industrial sectors have increased again since 2005; and without improved pollution controls or other actions to reduce mercury emissions, mercury emissions are likely to be substantially higher in 2050 than they are today.

\section{Objectives of the Joint Research Project "Traceability for Mercury Measurements"}

In this context, a Joint Research Project (JRP) entitled "Traceability for Mercury Measurements" (MeTra) started in October 2014 in the frame of the European Metrology Research Programme (EMRP) [5]. The project gathers 10 National Metrology Institutes and Designated Institutes from 7 European Countries, as well as 3 academic teams from 3 European Countries.

The project aims to address the following scientific and technical objectives:

- To develop a calibration infrastructure enabling the traceable assessment of mercury in air to support European legislation for gaseous emissions and air concentrations and as part of the global mercury observing system.

- To develop a metrological in-line measurement method and calibration infrastructure enabling the traceable assessment of mercury thresholds specified in European legislation and as part of the global mercury observing system for continuous and semi-continuous $\operatorname{Hg}(0)$ and $\mathrm{Hg}$ (II) measurement in (harsh) matrices like stationary source emissions or liquid media, including the use of sensor technology.

- To develop a metrological infrastructure for emerging requirements in mercury science such as the evaluation of mercury concentrations in indoor air from the use of mercury containing compact fluorescent lamps.
- To develop primary measurement procedures for mercury speciation in water and biota in order to improve mercury monitoring through the aquatic ecosystems and support European legislation [6, 7]. This will include the evaluation of transformation artefacts associated with sample collection and preparation, in order to minimise species conversion post-sampling.

- To develop and accurately perform bulk and compound specific isotope signature measurement methods for $\mathrm{Hg}(0)$ and $\mathrm{Hg}$ species.

- To develop and accurately perform light element (carbon) isotope ratio analyses in organo-Hg species in order to detect contaminant transformations and migration.

Furthermore, this project will investigate unique samples from the German Environmental Specimen Bank (ESB) that document large mercury concentration changes over the last decades. The analysis will employ the procedures developed and validated by the JRP to identify and track the sources and pathways of mercury in the environment. This will add significant value to the collection held under the ESB whilst also demonstrating the outputs of the JRP on real samples.

Specifically, the project aims to provide traceable assessment of mercury concentrations against those specified in European legislation, and as part of the global mercury observing system, through the development of a calibration infrastructure using an innovative primary mercury standard. The impact of this will be the validation of regional and global scale atmospheric mercury models that are used in the evaluation of different policy options for reducing mercury pollution impacts on human health and ecosystems.

Comparable and validated procedures will be enabled for continuous and semi-continuous $\mathrm{Hg}(0)$ and $\mathrm{Hg}(\mathrm{II})$ measurement in matrices like stationary source emissions particularly relevant to industrial sectors and the management of mercury contaminated sites, which will provide reliable calibration practices for in-line/in-situ methods and ensure faster measurement and comparable results.

Traceable methods for indoor mercury measurements will be implemented as part of the emerging requirements in mercury exposure from the use of mercury containing compact fluorescent lamps (CFLs). The impact of this will be the provision of consistent measurement data, which will support the implementation of EU Directive 2002/95/EC (RoHS Directive) [8].

Traceable measurements with uncertainty statements for mercury species in water and biota will also be provided, improving the limit of quantification and the measurement uncertainties of mercury monitoring and observing systems up to about one order of magnitude, as in the case of water, in order to understand temporal and spatial patterns of mercury transport and deposition to, and evasion from, terrestrial and aquatic ecosystems. 
Traceable measurements of bulk and compound specific mercury isotope ratio measurements will be developed as well as traceable light isotope measurements in order to get combined information on the locations of potential $\mathrm{Hg}$ sources and its fate and distribution pattern in the environment. This will provide consistent and comparable analytical tools to strengthen the policy relevance of basic research currently undertaken by numerous groups in Europe and worldwide to elucidate migration and transformation of environmental $\mathrm{Hg}$ and its compounds as well as for the identification of sources, sinks and pathways.

Engagement with users of measurement results, instrument producers, National Metrology Institutes outside Europe, standardisation bodies and policy makers has already been taken. This will allow strengthening the power of metrologically established methodologies in $\mathrm{Hg}$ measurements in support of the implementation of worldwide legislation and policy oriented research, ensuring the improvement of the reliability of the results and the consequent quality of decision making in $\mathrm{Hg}$ monitoring programs where correct evaluations are essential for human and environmental life.

\section{Conclusion and perspectives}

The JRP "Traceability for Mercury Measurements" (MeTra) has been launched in October 2014 and the experimental activities are under development.

By the end of the project, it is expected that the following achievements will be reached:

- Calibration facilities for $\mathrm{Hg}$ measurements in air traceable to SI units will be available;

- Procedures for continuous and semi-continuous $\mathrm{Hg}(0)$ and $\mathrm{Hg}(\mathrm{II})$ measurement in matrices such as stationary source emissions will be fully validated;

- Procedures with uncertainty statements able to ensure comparable results for $\mathrm{Hg}$ and $\mathrm{MeHg}$ in water to support the implementation of the European Directives on the water quality monitoring will be accessible;

- Fish reference materials from the German Environmental Specimen Bank will be characterised for total mercury and mercury species;

- Traceable measurements of bulk and compound specific mercury isotope ratio measurements as well as light isotope $\left(\delta^{13} \mathrm{C}\right)$ measurements in fish samples will be available.

The project outcomes will provide the required metrological infrastructure for mercury measurements in all environmental media will be established as required by current and future national and international legislation aimed at controlling mercury emissions and releases. The implementation and assessment of the
Minamata Convention on mercury will also be supported, together with EC Directives and Member State objectives, to reduce the presence of mercury in the environment.

\section{References}

[1] European Directive 2004/107/EC relating to arsenic, cadmium, mercury, nickel and polycyclic aromatic hydrocarbons in ambient air.

[2] European Directive 2010/75/EU on industrial emissions (integrated pollution prevention and control).

[3] Minamata Convention on Mercury (www.mercuryconvention.org)

[4] UNEP document "Global Mercury Assessment" 2013.

[5] http://www.emrponline.eu/

[6] Directive 2000/60/EC establishing a framework for Community action in the field of water policy (Water Framework Directive - WFD.

[7] Directive 2013/39/EU amending Directives $2000 / 60 / \mathrm{EC}$ and 2008/105/EC as regards priority substances in the field of water policy.

[8] EU Directive 2002/95/EC on the restriction of the use of certain hazardous substances in electrical and electronic equipment RoHS Directive). 